\title{
The future of British surgery
}

\author{
JoHN A R SMITH
}

In his excellent book Hippocratic Oaths - Medicine and its Discontents Raymond Tallis fears that 'medicine may be reaching the end of its course as a profession'. He also fears that 'the present Government is in the process of removing control of postgraduate medical training from the control of the Royal Colleges' by the creation of the Postgraduate Medical Education and Training Board (PMETB).

Other challenges facing the profession include maintaining training standards in the face of the European Working Time Directive, the introduction of foundation programmes and Modernising Medical Careers (MMC), continuing professional development, and revalidation, to name but a few.

There has never been a time when it was more important for the profession in general and the surgical bodies in particular to work together to deliver a single voice for British surgery. For reasons of history within Great Britain and Ireland there are three surgical Royal Colleges and a Royal College of Physicians and Surgeons. There are specialty associations which meet under the umbrella of the Federation of Specialty Surgical Associations. Representatives of all these organizations meet quarterly under the auspices of the Senate of Surgery of Great Britain and Ireland, established in 1990.

Since 1969 higher surgical training has been organized by the Joint Committee on Higher Surgical Training (JCHST), responsible for the supervision of training in Great Britain and Ireland, and since 1993 the Specialty Fellowship Examination has been organized by the Joint Committee on Intercollegiate Examinations. Similar bodies exist for basic surgical training and examinations but will be subsumed within the MMC framework.

For most specialties there is one body for the whole of the United Kingdom. Although there are three Colleges of Physicians within the United Kingdom they operate in tandem under the umbrella of the Federation of the Royal Colleges of Physicians of the United Kingdom. For most other specialties, there is only one body for the whole of the United Kingdom.

Each surgeon in Great Britain has an allegiance to at least one surgical college and to a specialty association. The remit of colleges and specialty associations is different but it is important to recognize that none of the surgical colleges have a defined geographical sphere of influence in their charter.
The contribution of colleges to fund the JCHST is based on the numbers of fellows and members affiliated to each college and currently comprises 43 per cent from the Royal College of Surgeons of England, 38 per cent from the Royal College of Surgeons of Edinburgh, 15 per cent from the Royal College of Physicians and Surgeons of Glasgow, and 8 per cent from the Royal College of Physicians in Ireland. Further evidence that geography alone does not count comes from the recognition that over 8000 members and fellows of the Royal College of Surgeons of Edinburgh live and work in England and Wales, of whom approximately 6000 are affiliated only to that college. Some would argue that colleges should relate to the home country and mistake devolution in Scotland for separatism. However the profession must surely rise above such political divisions and work collectively for the betterment of standards of patient care throughout Great Britain and Ireland.

Clearly there are some matters relating to heritage and history which are truly collegiate and must be preserved as such. In many other areas there is a strong case for much greater collaboration between the interested parties in order to be cost-effective and to avoid reduplication of expenditure, time and available personnel. We are all aware of the increased pressures on consultant time which the new contract has created and of the need to devote time and resources to educational supervision, examining, visits of inspection etc., all of which are National Health Service duties usually undertaken on behalf of the Health Service by the colleges.

Surely now is the time for a wide-ranging debate on intercollegiality and the future relationships between colleges and specialty associations. A number of colleges and specialty associations have indicated that they are fully in favour of such a debate and have expressed a hope that this would result in a single and stronger voice for British surgery. Other councils are not convinced of the merits of this argument but this is a debate which should involve all surgeons and not be confined to elected members of council.

\section{Proposals for debate}

(1) There should be one body which speaks for British surgery. This could be the Senate of Surgery but could also be a Federation of Colleges and 
Specialty Associations. Hopefully such a development would lead to the establishment of a Royal College of Surgery for Great Britain. This could easily be a virtual college based on the campuses which already exist. It is likely that such an evolution would take five to 10 years.

(2) There should be one council for matters which relate specifically to British surgery. It would be necessary to have separate councils for the specifics relating to individual colleges and associations. These would also act as trustees for heritable property.

(3) Affiliation to an individual college should continue as at present, i.e. the candidate has free choice, until we have established a mechanism for ensuring that one surgical body meets the needs of both trainees and established specialists. The suggestion is that all guidelines for activities would come from the central body but would be delivered on one or more of the four campuses.

(4) Achieving a just proportionality of influence, council membership, etc. may be difficult. We already have a formula from the funding of the JCHST which could be used for this purpose.

(5) Ideally no college should be allowed to wither or die as a result of any proposal about the colleges and associations working more closely together. The use of all available campuses should avoid such an eventuality.

(6) Each campus could be given defined responsibilities on behalf of all members of the unified body. This would be based on expertise which currently exists but would be governed by a series of intercollegiate committees.

\section{Benefits}

The potential benefits of these proposals are clear.

(1) We would have one voice, i.e. a consensus voice for surgery for Great Britain and Ireland.

(2) There would be clear lines of communication between the profession and all government bodies.

(3) We would provide a united front for discussion with new bodies such as the PMETB.

(4) We would avoid duplication of effort, overlap of activities and wastage of precious resources.

This paper is presented to encourage wider debate and it is hoped that all surgeons will feel able to comment on the proposals in order to guide current councils as to their preferred way forward. 